\title{
ECO-DESIGN ACTIONS TO IMPROVE LIFE CYCLE ENVIRONMENTAL PERFORMANCE OF FACE MASKS IN THE PANDEMIC ERA
}

\author{
Boix Rodríguez, Núria (1); \\ Marconi, Marco (2); \\ Favi, Claudio (1); \\ Formentini, Giovanni (1) \\ 1: Università degli Studi di Parma; \\ 2: Università degli Studi della Tuscia
}

\begin{abstract}
Face masks are currently considered essential devices that people must wear today and in the near future, until the COVID-19 pandemic will be completely defeated through specific medicines and vaccines. Such devices are generally made of thermoplastic polymers, as polypropylene and polyethylene and are single use products. Even if in this period the sanitary emergency must have the maximum priority, the world society should not completely forget the environmental problem that are causing more and more obvious climate changes with correlated damages to ecosystems and human health. Despite the well-known correlation among anti-COVID protective equipment (or more generally medical devices) and environmental issues, the Life Cycle Assessment (LCA) and ecodesign-based studies in this field is very scarce. The present study aims to derive the most important environmental criticalities of such products, by using LCA and product circularity indicators of five different common masks. The final aim is to provide eco-design guidelines, useful to design new face masks by preventing negative impact on the environment.
\end{abstract}

Keywords: Face mask, Ecodesign, COVID-19, Circular economy, Sustainability

\section{Contact:}

Boix Rodríguez, Núria

Università degli Studi di Parma

Department of Engineering and Architecture

Italy

nuria.boixrodriguez@unipr.it 


\section{INTRODUCTION}

At the middle of March 2020, the World Health Organization (WHO) officially declared that the epidemic originated in China by the new SARS-CoV-2 virus became a pandemic. From that day the world society is constantly involved in finding a solution to defeat this new invisible enemy or at least to find a mitigation solution (Rowan and Laffey, 2020). In this sense, the most effective ways to contain the infection consist in limiting the contacts among people and to protect the people respiratory tract. Indeed, even if the virus can be transmitted by direct contact with other infected persons, or indirect contacts with objects, the most important cause of contagion is certainly the airborne transmission, through droplets or aerosol (Chaudhuri et al., 2020). This is the reason why face masks, which work as physical barriers, are considered essential devices that people must wear until the virus will be completely defeated through specific medicines and vaccines (Leung et al., 2020; Zhang et al., 2020). However, "traditional" face masks (both surgical masks and personal protective equipment - PPE) are generally made of thermoplastic polymers, like polypropylene and polyethylene (Pu et al., 2018) and are single use products (SUP). The sudden increase in demand firstly caused a shortage of face masks and material needed for their fabrication (mainly non-woven fabrics) in numerous countries in the last months (Chiang et al., 2020; Ji et al., 2020). In addition, it has a direct negative impact on the world environmental issues, due to the increase in consumption of fossil-based resources and in generation of plastic waste that are very difficult to recover. Even if in this period the sanitary emergency must have the priority against all other issues, the world society should not completely forget the environmental problem that are causing more and more obvious climate changes with correlated damages to ecosystems and human health (Kumar et al., 2020; Singh et al., 2020, Rowan and Laffey, 2021). Some recent studies claim that plastic-based masks are a new relevant form of SUP waste (Euronews, 2020) that without improving the current waste management systems and policies it will be landfilled, it will cause important green-house gas (GHG) emissions (Zheng and Suh, 2019), and it will represent a primary source of micro-plastics dangerous for both ocean microorganisms and the human health when re-enter in the human food chain (Fadare and Okoffo, 2020). Such issues are faced in the scientific literature that, on one side investigated the possibility to develop sustainable end of life processes (Jung et al., 2021), and on the other side focused on the implementation of reuse scenarios to extend the product lifetime, as well as in the development of more sustainable products through eco-design approaches. To this aim, few studies are focused on estimating the possibility and positive impacts (both in economic and environmental terms) of reusing devices in the healthcare sector (McGain et al., 2017; Ertz and Patrick, 2020). More specifically in the field of face masks, Allison et al. (2020) and Kumar et al. (2020) quantified the benefits, in terms of waste generation and environmental impacts, deriving from improved masks end of life scenarios (reuse and decentralized incineration, respectively). A proper material selection, adequate design choices, a guide for final users and the correct end of life management towards closed-loop lifecycles (i.e. sanitization and reuse) are effective measures to reduce the energy and carbon footprint of face masks and PPE (Klemeš et al., 2020). In this sense, additive manufacturing seems promising for the development of reusable devices. Technical factors, testing recommendations and biological concerns (i.e., biocompatibility and sterilization) for medical devices developed with additive manufacturing techniques were investigate as a possible solution to overcome the shortage of protective gear (Tarfaoui et al., 2020).

Despite the well-known correlation among anti-COVID protective equipment (or more generally medical devices) and environmental issues, the Life Cycle Assessment (LCA) and eco-design-based studies in this field is very scarce (Sousa et al., 2020). In this context, starting from an LCA analysis of the most common face masks typologies, the present study aims to derive the most important environmental criticalities of such products. The research study has been carried out using a two steps methodology: (i) Environmental and circularity KPI assessment; and (ii) Knowledge based system for eco-design. The final aim is to provide a set of eco-design guidelines that can be used to design new face masks by preventing negative impact on the environment.

The paper is structured as follows. After Introduction that analyses the context and relevant literature, Materials and methods describes the methodologies used for the analyses of the face masks environmental impacts and circularity. Results section details the obtained results and criticalities for each of the five analysed masks. Finally, Discussion and conclusion section discusses the main outcomes of the study, the eco-design guidelines to be used for future developments of new face masks. 


\section{MATERIALS AND METHODS}

The research study has been carried out using a two steps methodology: (i) Environmental and circularity KPI assessment; and (ii) Knowledge based system for eco-design. The first step includes the use of various types of indicators, in order to have an analysis as complete and detailed as possible. Specifically, the LCA methodology (of great value for eco-design actions), in combination with a circularity evaluation (through the Material Circularity Indicator), were the starting point to identify product criticalities. Concerning the estimation of the environmental impacts correlated to face masks manufacturing and use during the sanitary emergency, the analyses have been carried out by following the 4 steps of the LCA methodology, included in the ISO 14040 - 14044 standards: (i) Goal and Scope definition, (ii) Life Cycle Inventory - LCI, (iii) Life Cycle Impact Assessment - LCIA, and (iv) Interpretation. The functional unit selected for the comparison is defined as follow: "The use of a face mask that guarantee the filter efficiency of at least $90 \%$ able to prevents the emission of respiratory droplets, in a pandemic situation for Italian citizen during a month". As it is uncertain how long the COVID-19 pandemic will last, it has been decided to set the analysis period at 1 month. In this way, total impacts can be easily calculated by multiplying such monthly results by the duration. In addition, a specific country (Italy), was selected as a reference country for this study. For the purpose of comparing on an equivalent basis the product alternatives, the reference flow (Weidema et al., 2004) has been established as a face mask compliant with UNI EN 149-2009 or UNI EN 14683-2019 standards. The system boundaries can be seen in Figure 1, where raw materials are transported by ship (China-Italy) and masks are transported by truck inside the country (Italy).

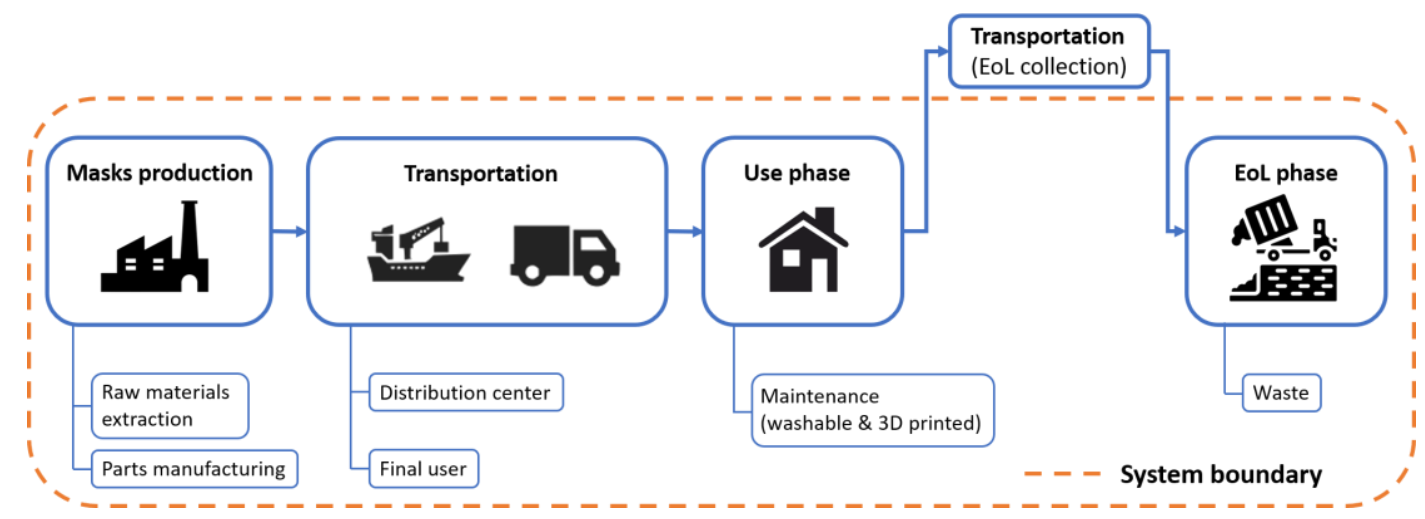

Figure 1. System boundary

Five different masks have been analysed for this study. The first model (M1) uses disposable FFP2 filters and a 3D printed structure. Second mask (M2) is a surgical mask which needs to be discarded every 4 hours of use. M3 is a FFP2 mask which includes an exhalation valve to improve breathing, protecting the user from external contamination but not other people. M4 is a FFP2 mask without valve, for this reason provides double protection (for the user and also for the rest of the people). Both masks (M3 and M4) need to be discarded every 8 hours of use. Finally, M5 is a washable mask that can be reused several times, maintaining its filtering properties for at least 50 washes.

The inventory (LCI) includes all the environmental inputs and outputs associated. Two phases can be distinguished: manufacturing and use. In order to obtain the necessary data for the LCI manufacturingphase, the five types of mask have been disassembled to the constituent materials. Table 1 shows this information. It is worth noting that for the M1 mask the manufacturing process (additive manufacturing) was considered within the system boundaries, while for the other mask typologies the manufacturing processes were neglected due to lack of data. Material weight has been measured using specific equipment. For the LCI use-phase it must be taken into account that the study is being carried out on the Italian scenario, where the daily need for masks is about 40 million (Ispra, 2020). In the chosen time frame (i.e. one month), the need for the different typologies of face masks are the following:

- M1: 40 million masks + 600 million filters;

- M2: 1200 million;

- M3: 600 million;

- M4: 600 million;

- M5: 40 million. 
Table 1. LCl data

\begin{tabular}{|c|c|c|c|c|}
\hline Type & Image & Useful life & Material & Weight [g] \\
\hline \multirow[t]{4}{*}{ M1 } & & \multirow{4}{*}{$\begin{array}{l}\text { FFP2 filters: } 8 \mathrm{~h} \\
\text { (Lepelletier et al., } \\
\text { 2020) }\end{array}$} & PP - Polypropylene (filter) & 0,50 \\
\hline & & & PE - Polyester (filter) & 0,50 \\
\hline & & & PLA (mask) & 30,00 \\
\hline & & & Synthetic rubber (bands) & 3,00 \\
\hline \multirow[t]{4}{*}{ M2 } & & \multirow{4}{*}{$\begin{array}{l}\text { 4h } \\
\text { (Lepelletier et al., } \\
2020)\end{array}$} & PP - Polypropylene (filter) & 1,28 \\
\hline & & & PE - Polyester (filter) & 1,28 \\
\hline & & & Aluminium (nose adapter) & 0,44 \\
\hline & & & Cotton (bands) & 0,02 \\
\hline \multirow[t]{5}{*}{ M3 } & & \multirow{5}{*}{$\begin{array}{l}8 \mathrm{~h} \\
\text { (Lepelletier et al., } \\
2020)\end{array}$} & PP - Polypropylene (filter) & 5,00 \\
\hline & & & PP - Polypropylene (valve) & 5,00 \\
\hline & & & Aluminium (nose adapter) & 0,95 \\
\hline & & & PU - Polyurethane foam (nose protection) & 0,05 \\
\hline & & & Synthetic rubber (bands) & 3,00 \\
\hline \multirow[t]{3}{*}{ M4 } & & \multirow{3}{*}{$\begin{array}{l}8 \mathrm{~h} \\
\text { (Lepelletier et al., } \\
2020)\end{array}$} & PP - Polypropylene (filter) & 5,00 \\
\hline & & & Aluminium (nose adapter) & 0,95 \\
\hline & & & Synthetic rubber (bands) & 3,00 \\
\hline \multirow[t]{3}{*}{ M5 } & & \multirow{3}{*}{\begin{tabular}{|l}
50 washes \\
(Jonel, 2020)
\end{tabular}} & PP - Polypropylene (filter) & 2,70 \\
\hline & & & PE - Polyester (filter) & 2,70 \\
\hline & & & Cotton (bands) & 1,00 \\
\hline
\end{tabular}

During the use phase the M5 (washable mask) requires "maintenance", since it must be washed with a consumption of water, electricity and soap (it has been considered that a washing machine is used). In case of M1 (3D printed mask), instead, the plastic part must be disinfected with ethanol before reuse. Finally, for the end-of-life (EoL) phase, it has been considered a scenario in which all devices are disposed as non-sanitary wastes (municipal landfill). The SimaPro 9.0.0.49 software tool, equipped with Ecoinvent 3.5 database as source of secondary data, was used to carry out the Life Cycle Impact Assessment (LCIA). Two different methods have been used to obtain the impact indicators according to the scope. First of all, ReCiPe that allows to obtain an overview of the environmental loads. Midpoints and endpoints were investigated. Of the 18 categories of midpoints offered by this method, global warming potential (GWP) and fossil resource scarcity (FFP) have been analysed, thus obtaining indicators that affect human health, natural environment and resource scarcity (Huijbregts et al., 2016). Furthermore, to get a deeper knowledge of the damage to resource availability the endpoint resource scarcity (RA) was also used. Additionally, the Cumulative Energy Demand (CED) through Single Issue method, which includes both the direct and indirect consumption of energy related to the analysed lifecycle, was used (Hischier et al., 2010). Concerning the circularity evaluation, the Material Circularity Indicator (MCI) has been analysed to measure how restorative the material flows of a product was (Ellen MacArthur Foundation, 2015). This is intended to carry out an analysis that shares the vision of the EU and is aligned with it to achieve the objective to a circular economy (EC, 2020). To be able to quantify the MCI values (in the range 0 to 1 , being ' 0 ' fully linear and ' 1 ' fully circular), the MCI calculator tool (Goddin, 2020) was used (the minimum value for MCI that can be obtained with this calculator is 0,1 , meaning in this case fully linear). An essential parameter of the MCI index is the "utility" which is defined as in the equation (1):

$$
X=\left(\frac{L}{L a v}\right) \cdot\left(\frac{U}{U a v}\right)
$$

where $L$ is the lifetime of the product, $L a v$ is the industry average, $U$ is the number of functional units achieved during the use of a product and $U a v$ the industry average for similar products. In most cases only one of these ratios (i.e., $L / L a v$ ) will be used to calculate $X$, making the other ratio (i.e., U/Uav) equal to 1 (Ellen MacArthur Foundation, 2015).

The second step of the proposed methodology includes the possibility to translate environmental results to explicit knowledge that can be reused for the novel mask development. This step was performed in 
compliance with the guidelines of the international ISO 14006:2011 (updated in 2020), which establishes methodology and flowchart that must be followed to incorporate eco-design during the development of a product. The international ISO 14006:2011 is based on six phases: (i) Define product functions, (ii) Environmental analysis, (iii) Environmental improvement strategies, (iv) Develop environmental objectives, (v) Environmental product specification, and (vi) Develop technical solutions.

\section{RESULTS}

In this section, the outcomes are reported and discussed. Table 2 shows LCA results obtained for the five masks. Regardless of the metric, the greatest impact is produced by M3 (FFP2 mask with valve), followed by M4 (FFP2 mask without valve), M2 (surgical mask) and, with significantly lower results, by M1 (3D-printed mask with changeable filters) and M5 (washable mask).

Table 2. ReCiPe midpoints and endpoints and CED results

\begin{tabular}{|l|l|l|l|l|l|l|}
\hline Impact category & Unit & M1 & M2 & M3 & M4 & M5 \\
\hline GWP & kg CO2 eq. & $3,9 \mathrm{E} 6$ & $2,7 \mathrm{E} 7$ & $5,6 \mathrm{E} 7$ & $3,8 \mathrm{E} 7$ & $1,5 \mathrm{E} 6$ \\
\hline FFP & kg oil eq. & $1,2 \mathrm{E} 6$ & $7,3 \mathrm{E} 6$ & $1,7 \mathrm{E} 7$ & $1,1 \mathrm{E} 7$ & $4,1 \mathrm{E} 5$ \\
\hline RA & Dimensionless & $1,6 \mathrm{E} 1$ & $8,6 \mathrm{E} 1$ & $2,2 \mathrm{E} 2$ & $1,3 \mathrm{E} 2$ & $4,6 \mathrm{E} 0$ \\
\hline CED & MJ & $6,3 \mathrm{E} 7$ & $3,7 \mathrm{E} 8$ & $8,7 \mathrm{E} 8$ & $5,5 \mathrm{E} 8$ & $2,3 \mathrm{E} 7$ \\
\hline
\end{tabular}

If the two FFP2 masks are compared (M3 and M4) a difference of 36,5\% for FFP, 32,3\% for GWP and $39,3 \%$ for RA can be observed. Such results are due to the fact that M3 is composed of four different materials, one more than the M4. In addition, M3 has a more complex structure than the M4 (5 components vs 3 components), doubling the amount of PP used in the M4. M2 and M4 masks are both disposable devices. As mentioned above, the impact values of M4 are higher, specifically $31,2 \%$ for FFP and $28,9 \%$ for GWP, while considering the RA endpoint the difference is $34,6 \%$. The main reason for these results lies in the difference in weight (M4 weighs three times more than M2 mask), which makes the impact of M4 higher despite the fact that the lifespan of M4 is twice. M1 and M5 are devices whose useful life does not end after one use. As previously stated, M1 preserves the mask's structure (after being disinfected) while M5 can be washed. The fact that these masks are partly reusable means that their demand is much lower than the other types, which implies that the impacts are of an order of magnitude lower. If M1 and M5 are compared, it can be noticed that M1 values are higher with a difference of $65,8 \%$ for FFP, $61,5 \%$ for GWP and $70,8 \%$ for RA. This is mainly due to the higher weight of the device and the variety of materials used. For the CED results, it is observed that the highest values are also for M3, followed by M4, M2 and with an order of magnitude lower M1 and M5. Being the reasons of this outcomes analogous to those previously stated. A study of which components of each mask have a higher impact on the indicators analysed is shown below in Figure 2. This result allows to define eco-design actions focused on the parts that have the greatest impact. Concerning M1, the largest impacts in all categories are associated with the production of the mask structure (3D-printed). This highlights the importance of choosing a durable and easy to disinfect material that allows this component to be reused as many times as possible, offsetting this high initial impact during the device's use phase. Given the importance of the mask structure in case of M1, another material commonly used with 3D printers, the silicone, has been considered. Table 3 shows the different impact values for material and manufacturing phase. It can be seen how all indicators are higher in the case of silicone (with an average difference of 58,9\%), therefore the bio-based PLA material can be considered the best option.

Table 3. LCA comparison among PLA and silicone mask structures

\begin{tabular}{|l|l|l|l|}
\hline Impact category & Unit & PLA structure & Silicone structure \\
\hline GWP & kg CO2 eq & $1,4 \mathrm{E}-1$ & $4,0 \mathrm{E}-1$ \\
\hline FFP & kg oil eq & $3,7 \mathrm{E}-2$ & $9,5 \mathrm{E}-2$ \\
\hline RA & Dimensionless & $3,5 \mathrm{E}-7$ & $8,8 \mathrm{E}-7$ \\
\hline CED & MJ & $2,9 \mathrm{E} 0$ & $5,7 \mathrm{E} 0$ \\
\hline
\end{tabular}

In case of the surgical mask (M2) the largest impacts in almost all categories are associated with the material used to manufacture this type of mask except for GWP, where nose adapter presents the highest value. M3 mask is the type of mask with the higher number of components, although as shown in Figure $2 c$ the impact of nose protection is nearly negligible. The valve is the part with higher values 
for FFP and RA, thus the possibility to remove it can be considered a right eco-design practice. M4 mask is analogous to the M3 but without valve and nose protection, which implies a decrease in the overall impact during the manufacturing phase. Finally, for M5 the only category where bands have the greatest impact is on the GWP. Therefore, in order to improve the environmental aspects of this mask, actions should be focused on the filter material (reducing its weight or increasing its durability).

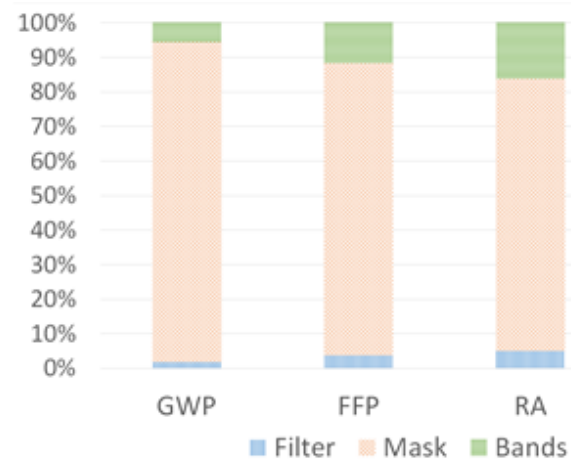

a) M1 mask

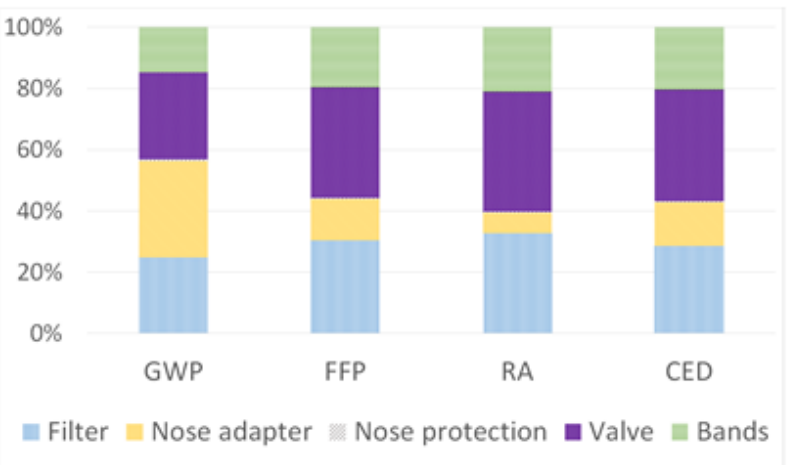

c) M3 mask

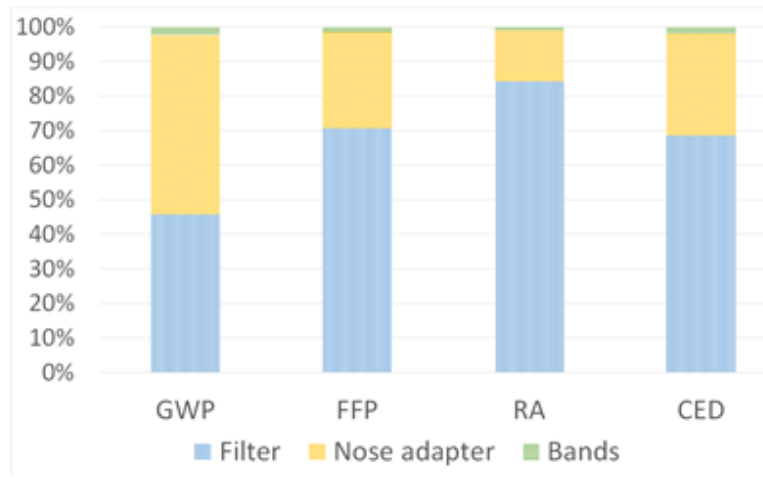

b) M2 mask
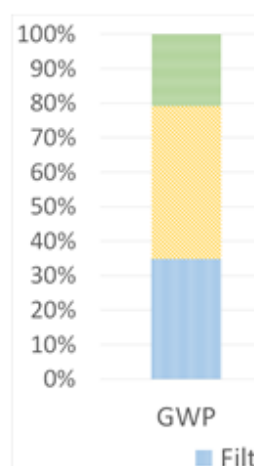

GWP

Filter
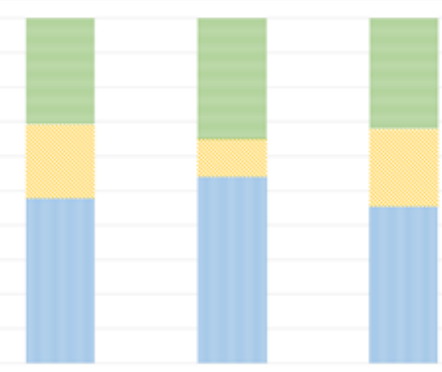

FFP

RA

CED

d) M4 mask

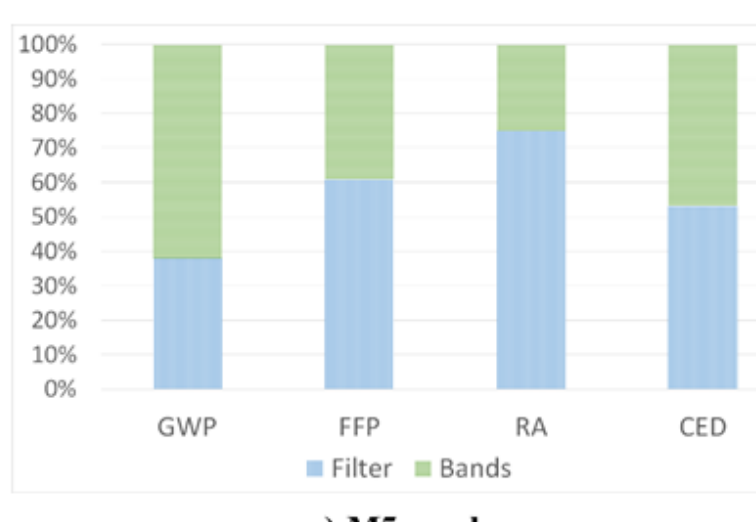

e) M5 mask

Figure 2. Detailed analysis (material and manufacturing phase) of the five analysed masks for the considered impact and damage categories

After the LCA, the circularity analysis has been carried out (Table 4). Starting with the 3D-printed mask (M1), the utility is based on the lifespan. Due to the fact that the useful life of the filter and mask structure is very different, it has been decided to calculate this index separately. Filters have a durability equal to the average of the FFP2 products $(X=1)$. On the other hand, the 3D printed structure might be set to limitlessness, however since it may suffer some damage, it is assumed that it has a durability of 300 times higher than a common FFP2 device which is $8 \mathrm{~h}(\mathrm{X}=300)$. Results show that M1 filter is a product fully linear, while the M1 structure is completely circular due to the very high utility. To improve this index and make the device more circular, the materials source should be changed, by using recycled or reused sources. Thus, filters are the critical parts and eco-design actions should focus on them. 
Table 4. MCl for the five analysed masks

\begin{tabular}{|c|c|c|c|c|c|c|}
\hline \multicolumn{7}{|c|}{ M1 filter } \\
\hline & & \multicolumn{2}{|c|}{ Input Materials } & \multicolumn{2}{|c|}{ Output Materials } & \multirow[t]{2}{*}{ MCI } \\
\hline Component & Weight [g] & Material & Source & Rate & Destination & \\
\hline Filter & 0,50 & $\mathrm{PP}$ & Virgin & $100 \%$ & Landfill & 0,1 \\
\hline Filter & 0,50 & PE & Virgin & $100 \%$ & Landfill & \multirow{3}{*}{$\begin{array}{r}0,1 \\
\text { Total MCI } \\
\mathbf{0 , 1} \\
\end{array}$} \\
\hline \multicolumn{2}{|c|}{ Product Mass $=1,00 \mathrm{~g}$} & & & & & \\
\hline \multicolumn{2}{|c|}{ Utility $=1$} & & & & & \\
\hline \multicolumn{7}{|c|}{ M1 structure } \\
\hline & & \multicolumn{2}{|c|}{ Input Materials } & \multicolumn{2}{|c|}{ Output Materials } & \multirow[t]{2}{*}{ MCI } \\
\hline Component & Weight [g] & Material & Source & Rate & Destination & \\
\hline Mask & 30,00 & PLA & Virgin & $100 \%$ & Landfill & 1 \\
\hline Bands & 3,00 & Synthetic rubber & Virgin & $100 \%$ & Landfill & 1 \\
\hline \multicolumn{2}{|c|}{ Product Mass $=33,00 \mathrm{~g}$} & & & & & \multirow{2}{*}{$\begin{array}{r}\text { Total MCI } \\
1\end{array}$} \\
\hline \multicolumn{2}{|c|}{ Utility $=300$} & & & & & \\
\hline \multicolumn{7}{|c|}{ M2 mask } \\
\hline & & \multicolumn{2}{|c|}{ Input Materials } & \multicolumn{2}{|c|}{ Output Materials } & \multirow[t]{2}{*}{ MCI } \\
\hline Component & Weight [g] & Material & Source & Rate & Destination & \\
\hline Filter & 1,28 & $\mathrm{PP}$ & Virgin & $100 \%$ & Landfill & 0,1 \\
\hline Filter & 1,28 & $\mathrm{PE}$ & Virgin & $100 \%$ & Landfill & 0,1 \\
\hline Nose adapter & 0,44 & $\mathrm{Al}$ & Virgin & $100 \%$ & Landfill & 0,1 \\
\hline Bands & 0,02 & Cotton & Virgin & $100 \%$ & Landfill & 0,1 \\
\hline \multicolumn{2}{|c|}{ Product Mass $=3,02 \mathrm{~g}$} & & & & & \multirow{2}{*}{$\begin{array}{r}\text { Total MCI } \\
0,1\end{array}$} \\
\hline \multicolumn{2}{|c|}{ Utility $=1$} & & & & & \\
\hline & & & 3 mask & & & \\
\hline & & Input Mater & ials & Outp & Iaterials & MCI \\
\hline Component & Weight [g] & Material & Source & Rate & Destination & \\
\hline Filter & 5,00 & $\mathrm{PP}$ & Virgin & $100 \%$ & Landfill & 0,1 \\
\hline Valve & 5,00 & $\mathrm{PP}$ & Virgin & $100 \%$ & Landfill & 0,1 \\
\hline Nose adapter & 0,95 & $\mathrm{Al}$ & Virgin & $100 \%$ & Landfill & 0,1 \\
\hline $\begin{array}{l}\text { Nose } \\
\text { protection }\end{array}$ & 0,05 & PU foam & Virgin & $100 \%$ & Landfill & 0,1 \\
\hline Bands & 3,00 & Synthetic rubber & Virgin & $100 \%$ & Landfill & 0,1 \\
\hline Product Mass & $14,00 \mathrm{~g}$ & & & & & Total MCI \\
\hline Utility $=1$ & & & & & & $\mathbf{0 , 1}$ \\
\hline & & & 4 mask & & & \\
\hline & & Input Mater & ials & Outp & Iaterials & MCI \\
\hline Component & Weight [g] & Material & Source & Rate & Destination & \\
\hline Filter & 5,00 & $\mathrm{PP}$ & Virgin & $100 \%$ & Landfill & 0,1 \\
\hline Nose adapter & 0,95 & $\mathrm{Al}$ & Virgin & $100 \%$ & Landfill & 0,1 \\
\hline Bands & 3,00 & Synthetic rubber & Virgin & $100 \%$ & Landfill & 0,1 \\
\hline Product Mass & $8,95 \mathrm{~g}$ & & & & & Total MCI \\
\hline Utility = 1 & & & & & & $\mathbf{0 , 1}$ \\
\hline & & & 5 mask & & & \\
\hline & & Input Mater & ials & Outp & Taterials & MCI \\
\hline Component & Weight [g] & Material & Source & Rate & Destination & \\
\hline Filter & 2,70 & $\mathrm{PP}$ & Virgin & $100 \%$ & Landfill & 0,9 \\
\hline Filter & 2,70 & $\mathrm{PE}$ & Virgin & $100 \%$ & Landfill & 0,9 \\
\hline Bands & 1,00 & Cotton & Virgin & $100 \%$ & Landfill & 0,9 \\
\hline Product Mass & $6,40 \mathrm{~g}$ & & & & & Total MCI \\
\hline Utility $=50$ & & & & & & $\mathbf{0 , 9}$ \\
\hline
\end{tabular}


For M2, M3 and M4 where material source is always "virgin", material destination is "landfill" and the utility is set to $1(\mathrm{X}=1)$. In these cases, the mask lifespan is equal to the market average, and it can be noticed how MCI value indicates that these products are fully linear. Lastly, the MCI of the M5 mask is calculated, obtaining an almost fully circular process. This is due to the fact that the lifetime of the product studied (washable mask) is much higher (50 times more) than the market average, so the utility is set to 50 $(\mathrm{X}=50)$. With this result, it is possible to appreciate the importance of increasing the lifespan of a product, which allows to improve MCI despite using virgin sources and landfilling the product at the EoL.

\section{DISCUSSION AND CONCLUSIONS}

In view of the above results and considering the objective of obtaining a more sustainable face mask against the virus diffusion, it can be concluded that the best option, considering both lifecycle environmental impacts and MCI, is the M5 mask, followed by M1. The results of this study demonstrate that reusable products are more environmentally sustainable than the widely spread disposable masks.

The presented analyses allow to identify different criticalities of each product and thus to derive a list of guidelines (eco-design action) to design an environmentally sustainable and circular face mask (following principles of ISO 14006:2011). Table 5 summarizes the defined guidelines.

Table 5. Eco-design guidelines for face masks

\begin{tabular}{|c|c|c|}
\hline Lifecycle phase & Criticalities observed & Related eco-design guidelines \\
\hline \multirow[t]{3}{*}{$\begin{array}{l}\text { Material and } \\
\text { manufacturing }\end{array}$} & $\begin{array}{l}\text { High impacts related to 3D } \\
\text { printing processes (M1) }\end{array}$ & $\begin{array}{l}\text { - To choose the most sustainable and low } \\
\text { energy intensive 3D printing processes } \\
\text { - To use other more sustainable manufacturing } \\
\text { processes (i.e., injection moulding), if a large } \\
\text { production volume of masks is required }\end{array}$ \\
\hline & $\begin{array}{l}\text { High impacts due to complex } \\
\text { structure (M3) }\end{array}$ & $\begin{array}{l}\text { - To reduce the number of components } \\
\text { (integrate parts with same material) } \\
\text { - To reduce the number of different materials } \\
\text { used for the masks } \\
\text { - To avoid outlet valve }\end{array}$ \\
\hline & $\begin{array}{l}\text { High impacts and low } \\
\text { circularity due to the use of } \\
\text { virgin materials (M1, M2, } \\
\text { M3, M4, M5) }\end{array}$ & $\begin{array}{l}\text { - } \text { To choose more sustainable materials (e.g. } \\
\text { PP instead of PE) } \\
\text { - To avoid coupling PP and PE for the } \\
\text { manufacturing of filters (non-woven fabric) } \\
\text { - To use a mix of virgin and recycled input } \\
\text { materials (or if possible, only recycled } \\
\text { plastics) }\end{array}$ \\
\hline \multirow[t]{2}{*}{ Use } & $\begin{array}{l}\text { Single use products (M2, M3, } \\
\text { M4) }\end{array}$ & $\begin{array}{l}\text { - To prefer washable and reusable (fully or } \\
\text { partially) products }\end{array}$ \\
\hline & Low duration of filters (M1) & $\begin{array}{ll}\text { - } & \text { To develop new filter materials with higher } \\
\text { duration (i.e., surface activated filters) } \\
\text { (Perelshtein et al., 2009; Lazary et al., 2014; } \\
\text { Zhou et al., 2020) } \\
\text { - } \quad \text { To reduce the weight and surface of filters } \\
\text { - } \quad \text { To use washable and interchangeable filters }\end{array}$ \\
\hline \multirow[t]{3}{*}{ End of life } & $\begin{array}{l}\text { Multi-material for filters } \\
\text { reduces circularity (M1, M2) }\end{array}$ & - To use single materials \\
\hline & $\begin{array}{l}\text { Impossibility to separate } \\
\text { components and materials } \\
\text { (M2, M3, M4) }\end{array}$ & $\begin{array}{l}\text { - To develop products according to the design } \\
\text { for disassembly rules } \\
\text { - To minimize the number of components } \\
\text { - To use easy to disassemble joints (i.e., snap- } \\
\text { fit and press-fit) }\end{array}$ \\
\hline & $\begin{array}{l}\text { Open loop EoL (m1, M2, } \\
\text { M3, M4, M5) }\end{array}$ & $\begin{array}{l}\text { - To develop dedicated EoL processes for } \\
\text { material recycling } \\
\text { - To organize dedicated collection systems }\end{array}$ \\
\hline
\end{tabular}


In conclusion, this study demonstrated that LCA and MCI are useful tools to identify criticalities in the field of face masks. The abovementioned eco-design guidelines are useful suggestions for the development of new masks that effectively protect against the SARS-CoV-2 virus or other viruses and bacteria, without further compromising the environmental pollution.

Future studies will be focused on the main streams. The first one refers to the possibility to extend some of the emerged results to look at wider eco-design issues and maybe consider how to enable customers to select the most suitable mask and one with a lower environmental impact. The second one is the development of a new mask starting from user requirements and following a systematic design approach for the definition of a functional and modular structure. The identified eco-design guidelines will be essential to choose the most sustainable design alternatives considering a lifecycle perspective.

\section{REFERENCES}

Allison, A.L., Ambrose-Dempster, E., Aparsi, T.D., Bawn, M., Casas Arredondo, M., Chau, C., Chandler, K., Dobrijevic, D., Hailes, H., Lettieri, P., Liu, C., Medda, F., Michie, S., Miodownik, M., Purkiss, D. and Ward, J. (2020), "The environmental dangers of employing single-use face masks as part of a COVID-19 exit strategy", UCL Open: Environment Preprint. https://doi.org/10.14324/111.444/000031.v1

Chaudhuri, S., Basu, S., Kabi, P., Unni, V.R. and Saha, A. (2020), "Modeling the role of respiratory droplets in Covid-19 type pandemics", Physics of Fluids, Vol. 32, p. 063309. https://doi.org/10.1063/5.0015984

Chiang, J., Hanna, A., Lebowitz, D. and Ganti, L. (2020), "Elastomeric respirators are safer and more sustainable alternatives to disposable N95 masks during the coronavirus outbreak", International Journal of Emergency Medicine, Vol. 13, p. 39. https://doi.org/10.1186/s12245-020-00296-8

Ertz, M. and Patrick, K. (2020), "The future of sustainable healthcare: Extending product lifecycles", Resources, Conservation and Recycling, Vol. 153, p. 104589. https://doi.org/10.1016/j.resconrec.2019.104589

Ellen MacArthur Foundation (2015), Circularity Indicators: An Approach to Measure Circularity. Methodology.

Euronews (2020). Surge in marine plastic waste as people discard PPE used to ward off COVID-19. https://www.euronews.com/2020/06/25/surge-in-marine-plastic-wasteas-people-discard-ppe-used-to-wardoff-covid-19.

European Commission (EC) (2020), Communication from the Commission to the European Parliament, the Council, the Economic and Social Committee and the Committee of the Regions. A new Circular Economy Action Plan For a cleaner and more competitive Europe.

Fadare, O.O. and Okoffo, E.D. (2020), "Covid-19 face masks: A potential source of microplastic fibers in the environment”, Science of The Total Environment, Vol. 737, p. 140279. https://doi.org/10.1016/j.scitotenv.2020.140279

Goddin, J. (2020), A free Calculator for the Materials Circularity Indicator. Available at: https://www.hoskinscircular.com/blog/calculator-material-circularity-simple

Hischier, R., Weidema, B., Althaus, H J., Bauer, C., Doka, G., Dones, R and Nemecek, T. (2010). Implementation of Life Cycle Impact Assessment Methods.

Huijbregts, M.A.J., Steinmann, Z.J.N., Elshout, P.M.F., Stam, G., Verones, F., Vieira, M.D.M. and Van Zelm, R. (2016), ReCiPe 2016: a harmonized life cycle impact assessment method at midpoint and endpoint level report I: characterization.

Ispra (2020), I rifiuti costituiti da DPI usati. Available at: https://www.isprambiente.gov.it/files2020/notizie/rapporto-ispra-dpi-usati_1905.pdf

Ji, D., Fan, L., Li, X. and Ramakrishna S. (2020), "Addressing the worldwide shortages of face masks", $B M C$ Materials, Vol. 2, p. 9. https://doi.org/10.1186/s42833-020-00015-w

Jonel (2020), Elsanek Olefine 150. Available at: http://www.jonelsl.com/wpcontent/uploads/2020/07/fitxa_150_Olefine_2020.pdf

Jung, S., Lee, S., Dou, X. and Kwon, E.E. (2021), "Valorization of disposable COVID-19 mask through the thermo-chemical process", Chemical Engineering Journal, Vol. 405, p. 126658. https://doi.org/10.1016/j.cej.2020.126658

Klemeš, J.J.K., Van Fan, Y. and Jiang, P. (2020), “The energy and environmental footprints of COVID-19 fighting measures - PPE, disinfection, supply chains", Energy, Vol. 211, p. 118701. https://doi.org/10.1016/j.energy.2020.118701

Kumar, H., Azad, A., Gupta, A., Sharma, J., Bherwani, H., Labhsetwar, N.K. and Kumar, R. (2020), “COVID19 Creating another problem? Sustainable solution for PPE disposal through LCA approach", Environment, Development and Sustainability. https://doi.org/10.1007/s10668-020-01033-0

Lazary, A., Weinberg, I., Vatine, J.-J., Jefidoff, A., Bardenstein, R., Borkow, G., Ohana, N. (2014), "Reduction of healthcare-associated infections in a long-term care brain injury ward by replacing regular linens with biocidal copper oxide impregnated linens", International Journal of Infectious Diseases, Vol. 24, pp. 23-29 
Lepelletier, D., Grandbastien, B., Romano-Bertrand, S., Aho, S., Chidiac, C., Géhanno, J.F. and Chauvin, F. (2020), "What face mask for what use in the context of COVID-19 pandemic? The French guidelines", Journal of Hospital Infection, Vol. 105, No. 3, pp. 414-418. https://doi.org/10.1016/j.jhin.2020.04.036

Leung, N.H.L., Chu, D.K.W., Shiu, E.Y.C., Chan, K.-H., McDevitt, J.J., Hau, B.J.P., Yen, H.-L., Li, Y., Ip, D.K.M., Peiris, J.S.M., Seto, W.-H., Leung, G.M., Milton, D.K. and Cowling, B.J. (2020), "Respiratory virus shedding in exhaled breath and efficacy of face masks", Nature Medicine, Vol. 26, pp. 676-680. https://doi.org/10.1038/s41591-020-0843-2

McGain, F., Story, D., Lim, T. and McAlister, S. (2017), "Financial and environmental costs of reusable and single-use anaesthetic equipment", British Journal of Anaesthesia, Vol. 118, No. 6, pp. 862-869. https://doi.org/10.1093/bja/aex098

Perelshtein, I., Applerot, G., Perkas, N., Wehrschuetz-Sigl, E., Hasmann, A. Guebitz, G., Gedanken, A. (2009), "CuO-cotton nanocomposite: Formation, morphology, and antibacterial activity", Surface and Coatings Technology, Vol. 204, No. 1-2, pp. 54-57. https://doi.org/10.1016/j.surfcoat.2009.06.028

Pu, Y., Zheng, J., Chen, F., Long, Y., Wu, H., Li, Q., Yu, S., Wang, X. and Ning, X. (2018), "Preparation of Polypropylene Micro and Nanofibers by Electrostatic-Assisted Melt Blown and Their Application", Polymers, Vol. 10, No. 9, p. 959. https://doi.org/10.3390/polym10090959

Rowan, N.J. and Laffey, J.G. (2020), "Challenges and solutions for addressing critical shortage of supply chain for personal and protective equipment (PPE) arising from Coronavirus disease (COVID19) pandemic Case study from the Republic of Ireland", Science of The Total Environment, Vol. 725, p.138532. https://doi.org/10.1016/j.scitotenv.2020.138532

Rowan, N.J. and Laffey, J.G. (2021), "Unlocking the surge in demand for personal and protective equipment (PPE) and improvised face coverings arising from coronavirus disease (COVID-19) pandemic Implications for efficacy, re-use and sustainable waste management", Science of The Total Environment, Vol. 752, p.142259. https://doi.org/10.1016/j.scitotenv.2020.142259

Singh, N., Tang, Y. and Ogunseitan, O.A. (2020), "Environmentally Sustainable Management of Used Personal Protective Equipment", Environmental Science \& Technology, Vol. 54, No. 14, pp. 8500-8502. https://doi.org/10.1021/acs.est.0c03022

Sousa, A.C., Veiga, A., Maurício, A.C., Lopes M.A., Santos, J.D. and Neto, B. (2020), “Assessment of the environmental impacts of medical devices: a review", Environment, Development and Sustainability. https://doi.org/10.1007/s10668-020-01086-1

Tarfaoui, M., Nachtane, M., Goda, I., Qureshi, Y. and Benyahia, H. (2020), “Additive manufacturing in fighting against novel coronavirus COVID-19", The International Journal of Advanced Manufacturing Technology, Vol. 110, pp. 2913-2927. https://doi.org/10.1007/s10668-020-01086-1

Weidema, B., Wenzel, H., Petersen, C. and Hansen, K. (2004), "The Product, Functional Unit and Reference Flows in LCA", Environmental News, Vol.70, pp.1-46

Zhang, R., Li, Y., Zhang, A.L., Wang, Y. and Molina, M.J. (2020), "Identifying airborne transmission as the dominant route for the spread of COVID-19”, PNAS, Vol. 117, No. 26, pp.14857-14863. https://doi.org/10.1073/pnas.2009637117

Zheng, J. and Suh, S. (2019), "Strategies to reduce the global carbon footprint of plastics", Nature Climate Changes, Vol. 9, pp. 374-378. https://doi.org/10.1038/s41558-019-0459-Z

Zhou, J., Hu, Z., Zabihi, F., Chen, Z., Zhu, M. (2020), "Progress and Perspective of Antiviral Protective Material”, Advanced Fiber Materials, Vol. 2, pp. 123-139. https://doi.org/10.1007/s42765-020-00047-7 